\title{
Surgical Treatment of Incompetent Perforator Veins by Subfascial Ligation
}

\author{
Dr. G Chandra Shekar Goud, Assistant Professor, Department of General Surgery, Prathima Institute of \\ Medical Sciences, Naganoor, Karimnagar, Telangana State, India.
}

Address for correspondence: Dr.G Chandra Shekar Goud, H.No1-1-166/3, Jambigadde, Jagtial, Telangana State, India. Email: shekhargoudatm@gmail.com

Submission: 15/1/2021

Review: 25/1/2021

Acceptance :3/2/2021

DOI:10.47799/pimr.0902.12

\section{ABSTRACT}

Background: Chronic venous ulceration of the leg is a common presentation in surgical clinics. Although, the majority of ulcers can be healed by simple compression. Some chronic ulcers with venous competencies require correction surgeries. We in the current study tried to study the role of Cockett and Dodd's operation of subfascial ligation of below-knee perforator veins in the treatment of varicose veins of the lower limbs.

Methods: This cross-sectional study was done in the Department of General Surgery, Prathima Institute of Medical Sciences, Naganoor, Karimnagar. $\mathrm{N}=40$ cases of varicosities of the lower limbs with perforatorincompetence with or without saphenofemoral incompetence. The patients were treated with perforator ligationalone with the Cockett and Dodd method or in combination with the stripping procedure.

Results: The clinical classification shows C5 healed venous ulcers and $\mathrm{C} 6$ active venous ulcers. $64 \%$ of cases belonged to these two categories and no case of $\mathrm{C} 1$ was found in our study. Perforator incompetence only was found in $n=25$ cases where perforator ligation alone was done given in table 4 . In $n=15$ cases, perforator ligation and stripping with or without ligation of sphenopopliteal junction was done. The minimal mean duration of stay was 5.5 days the maximal mean duration of stay was 8.0 days.

Conclusion: Open subfascial perforator ligation by Cockett and Dodd's procedure is a good procedure in the treatment of primary varicose veins with perforator incompetence. The rates of complications can be largely reduced by careful patient selection and skill full operative techniques. Follow-up of patients must be done at intervals for the development of new incompetent perforating veins and varicosities which may lead to the recurrence of ulcer formation.

Keywords: Subfascial ligation, varicose veins, Cockett and Dodd's method

\section{INTRODUCTION}

The first described case of varicose veins was by Sushruta in the second volume of his work Samhita, who discussed siragranthi or "aneurysms of veins" ${ }^{[1]}$. Hippocrates (460-377 B.C.) cauterized varicose veins with a hot iron rod. In his works, he has described a lot of cases of venous disease of the lower limbs. ${ }^{[2]}$ Porter et al; ${ }^{[3]}$ have classified varicose veins into seven classes according to the clinical signs and severity and disability rating scales. Varicose veins are defined as dilated usually tortuous subcutaneous veins of more than $3 \mathrm{~mm}$ diameter when measured in an upright position and demonstrable reflux. 4 . They are the result of prolonged erect posture. The risk of varicose veins is greater in females affects $25-30 \%$ of the population and males up to $15 \%$. ${ }^{[4]}$ The risk factors for the development of varicose veins are advancing age, female gender, heredity, and history of trauma to the extremity. ${ }^{[5]}$ The presence of varicose veins causes the development of symptoms of which most common being the aching or heaviness, gradually increasing throughout the day. Other symptoms include ankle swelling and itching. 4 sometimes a burning sensation called venous neuropathy also occurs in some cases with advanced venous insufficiency. [5]The signs include dilated tortuous veins, telangiectasis, and fine reticular varicosities. The competency of the venous system effected in the superficial venous system, deep venous system, or perforating veins. If the incompetent perforators are not properly localized and ligated, they may complete the circuit of varicose veins draining blood from deep to superficial venous system leading to recurrence. ${ }^{[6]}$ The clinical examination is done for localization of the site of incompetence to determine superficial or deep veins involved. In the superficial system, the problem usually occurs in the saphenofemoral or saphenopopliteal junction or at the perforator level. The test to determine it is Brodie Trendelenburg test, Tourniquet test, Perth's test, Schwartz test, Pratt's test, and Fegan's test. The clinical tests are combined with other diagnostic modalities 
such as duplex ultrasound imaging which can exactly identify the incompetent sites and minimally invasive surgeries can be performed. ${ }^{[7]}$ with this background, we in this study tried to determine the role of Cockett and Dodd operation of subfascial ligation of below-kneeperforator veins in the treatment of varicose veins of the lower limb.

\section{Material and Methods}

This prospective study was conducted in the Department of General Surgery, Prathima Institute of Medical Sciences, Naganoor, Karimnagar. Written consent was obtained from all the participants of the study.

Inclusion criteria

1. Patients diagnosed with primary varicosities of the great or small saphenous system with perforator incompetence.

2. Patients were willing to voluntarily participate in the study.

Exclusion criteria

1. Patients with varicose veins not having perforator vein incompetence (those with

2. saphenofemoral or saphenopopliteal incompetence only) where not included in the study.

3. Patients with deep venous thrombosis were excluded from the study.

A thorough history and clinicalexamination were done to assess the venous system. The location of the varicosities, thepresence or absence of skin pigmentation, edema, dermatitis, ulceration, etc.They were subjected to routine biochemical investigations (complete bloodpicture, complete urine exam, random blood sugar, blood urea, serum creatinine) androutine imaging (Chest Roentgenogram), and an electrocardiogram. A Duplex study of thevenous system was done preoperatively to assess the extent of the varicosities, thepresence or absence ofsaphenofemoral incompetence, saphenopopliteal incompetence,perforator veinincompetence, and the status of the deep veins. Those patients withoutperforator incompetence were excluded from the study. For patients with venous ulceration, conservative management with daily salinedressings and elastocrepe bandage application was done till the active infection subsided.Patients were taken up for surgery once the inflammation and infection subsided and theulcer floor was clean and granulating. Patients were not made to wait until completehealing of the ulcer.All patients were operated on in elective operating rooms with strict asepticprecautions. Anesthesia used was spinal anesthesia in all the patients.They were treatedwith perforator ligation alone or perforator ligation plus stripping and saphenopoplitealligation wherever applicable.Perforator ligation was done by the Cockett and Dodd method.[8, 9]

\section{Results}

Out of the total of $n=40$ cases, $n=36(90 \%)$ patients were male and $n=4(10 \%)$ patients were females. The mean age group in male cases was $61.5 \pm 2.5$ years and the mean age of females was $57.5 \pm 1.5$ years. The youngest male case was 45.0 years and oldest was 69.5 years and the youngest female patient was 48.5 years and the oldest was 66.5 years. Although both sides were almost equally involved predominance of the left side was in $47.5 \%$ of cases and bilateral involvement was in $10 \%$ of cases depicted in table 1.

Table 1: Side involved in the cases of study

\begin{tabular}{|c|c|c|}
\hline Side involved & frequency & percentage \\
\hline Right lower limb & 17 & 42.5 \\
\hline Left lower limb & 19 & 47.5 \\
\hline Bilateral & 4 & 10.0 \\
\hline Total & 40 & 100 \\
\hline
\end{tabular}

The clinical classification depicted in table 2 shows $\mathrm{C5}$ healed venous ulcers and $C 6$ active venous ulcers. $64 \%$ of cases belonged to these two categories and no case of $\mathrm{C} 1$ was found in our study.

Table 2: Clinical classification of varicose veins

\begin{tabular}{|c|c|c|}
\hline Clinical classification & Frequency & percentage \\
\hline C1 & 0 & 0.00 \\
\hline C2 & 6 & 15.0 \\
\hline C3 & 5 & 12.5 \\
\hline
\end{tabular}




\begin{tabular}{|c|c|c|}
\hline C4 & 5 & 12.5 \\
\hline C5 & 8 & 24.0 \\
\hline C6 & 16 & 40.0 \\
\hline
\end{tabular}

The etiological classification showed in table 3 all the $100 \%$ cases were $\mathrm{Ep}$ (primary category) of ulcers. Based on the anatomical classification perforator veins were involved most

\begin{tabular}{|c|c|c|}
\hline Etiological Classification & frequency & percentage \\
\hline Class & 0 & 0.0 \\
\hline Ec & 40 & 100 \\
\hline Ep & 0 & 0.0 \\
\hline Es & \multicolumn{2}{|c|}{} \\
\hline Anatomical classification & 0 & 0.0 \\
\hline As & 25 & 62.5 \\
\hline Ap & 15 & 37.5 \\
\hline Asp & & 100 \\
\hline Pathophysiologic classification & 40 & 0.0 \\
\hline Pr & 0 & 0.0 \\
\hline Po & 0 & \\
\hline PRO & T & \\
\hline
\end{tabular}

Perforatorincompetenceonly was found in $n=25$ cases where perforator ligation alone was done given in table 4 . In $\mathrm{n}=15$ cases, perforator ligation and stripping with or without ligation of sphenopopliteal junction was done. The minimal

mean duration of stay was 5.5 days the maximal mean duration of stay was 8.0 days.

Table 4: The type of surgery performed along with the duration of stay of each procedure

\begin{tabular}{|c|c|c|c|}
\hline \multirow{2}{*}{ Procedure } & \multicolumn{2}{|c|}{ Surgery } & \multirow{2}{*}{ Mean duration of hospital stay } \\
\cline { 2 - 3 } & frequency & Percentage & \\
\hline \multicolumn{1}{|c|}{ Perforator ligation alone } & 25 & 62.5 & 5.5 days \\
\hline $\begin{array}{l}\text { Perforator ligation and Stripping (with/ } \\
\text { without ligation of the saphenopopliteal } \\
\text { junction }\end{array}$ & 15 & 37.5 & 8.0 days \\
\hline
\end{tabular}

The total number of cases with varicose ulcers were $\mathrm{n}=16$. The minimal healing time of ulcers in the cases was 6.5 days and the maximum healing time was 7 weeks. The average healing time of ulcers was 4.5 weeks. The most common complication recorded was residual perforator incompetence in $7.5 \%$ of cases and wound infection was recorded in $5.0 \%$ commonly in $62.5 \%$ of cases. Based on the pathophysiological classification the $100 \%$ of cases were of reflux causes.

Table 3: Etiological, anatomical, and pathophysiologic classification
Table 5: Complications of surgery in the cases of study 


\begin{tabular}{|c|c|c|}
\hline Complications of surgery & frequency & 7.5 \\
\hline Residual perforator incompetence & 3 & 5.0 \\
\hline Wound Infection & 2 & 5.0 \\
\hline Delayed wound healing & 2 & 0.0 \\
\hline Hematoma & 0 & 0.0 \\
\hline Nerve palsy & 0 & \\
\hline
\end{tabular}

\section{Discussion}

In the current study out of the $\mathrm{N}=40$ cases, $\mathrm{n}=36(90 \%)$ patients were male and $n=4(10 \%)$ patients were females.They could be because of social reasons females are hesitant to seek medical intervention for this problem. SN Kumar et al; ${ }^{[10]}$ in a similar study found out of $n=26$ cases $n=23$ was male and $n=3$ were female cases. In this study, $\mathrm{n}=16$ cases were $\mathrm{C} 5$ category with active ulcers. The active ulcers with infection and slough were preoperatively managed with debridement and daily dressing till the infection come down and the ulcer floor was covered with healthy granulations. In this study, the cases with isolated perforator incompetence were treated with Cockett and Dodd procedure whereas patients with saphenofemoral incompetence underwent stripping operation along with subfascial ligation. The follow-up cases were done every 2 weeks for 12 weeks to find any cause of complication and treat them as required. Friedgood et al; ${ }^{[11]}$ in 109 cases found $84 \%$ of cases healed with subfascial ligation of incompetent perforating veins by using the Linton and Dodd method. Other studies have also described good to excellent results after surgical therapy directed on the perforating veins. ${ }^{[12,13]}$ Negus $\mathrm{D}^{[14]}$ followed 1000 cases for the 9 years and overall recurrence rates were $10 \%$. The recent reports of recurrence suggest the recurrence rate was $15 \%$ in 767 limbs. ${ }^{[15]}$ The minimal healing time of ulcers in the cases was 6.5 days and the maximum healing time was 7 weeks. Negus et al; ${ }^{[14]}$ in 108 cases found ulcer healing time was 17 days and the healing rate was $84 \%$. Tikrit et al; ${ }^{[15]}$ reported ulcer healing of only $30 \%$ with an average healing time of 6 weeks. The most common complication recorded was residual perforator incompetence in $7.5 \%$ of cases and wound infection was recorded in $5.0 \%$ and wound infections in $5.0 \%$ cases. The complications of surgeries range from DVT. Pulmonary embolism, flap necrosis, wound infections, and other complications. Stuart et al; [16] found $45 \%$ local wound complication rates for subfascial ligation procedures. Bowen et al; found $44 \%$ wound infection in cases undergoing open perforator surgery by comparing the Cockett and Dodd procedure with SEPS. In this study, SEPS procedures were not undertaken due to economical technical reasons. Sybrandy et al; ${ }^{[17]}$ compared the recurrence rates with perforator ligation and SEPS and concluded that ulcer healing times are similar in both surgeries. The minimal mean duration of stay was 5.5 days the maximal mean duration of stay was 8.0 days. Stuart et al; ${ }^{[16]}$ reported duration of stay of 9 days in open perforator ligation however recurrence rates were not determined due to lack of long-term follow-up. A long-term follow-up study by Negus D ${ }^{[14]}$ found $84 \%$ were free of ulcerations upto 6 years after open perforator ligation surgery.

\section{Conclusion}

Open subfascial perforator ligation by Cockett and Dodd's procedure is a good procedure in the treatment of primary varicose veins with perforator incompetence. The rates of complications can be largely reduced by careful patient selection and skill full operative techniques. Follow-up of patients must be done at intervals for the development of new incompetent perforating veins and varicosities which may lead to the recurrence of ulcer formation.

\section{REFERENCES}

1. In: Adams EF, ed. Hippocrates: The Genuine Works of Hippocrates, vol 2. New York: Wm Wood \& Co; 1886:305.

2. Ruehm SG, Zimny K, Debatin JF. Direct contrast-enhanced 3D MR venography, Eur Radiol. 2001. 11: 102-112.

3. Porter JM and Moneta GL. Reporting standards in venous disease: An update international consensus committee on chronic venous disease. J. Vasc Surg. 1995; 21(4): 635645.

4. Babcock WW: A new operation for extirpation of varicose veins of the leg. N Y Med J 1907; 86:153.

5. Linton RR: The post-thrombotic ulceration of the lower extremity: Its etiology and surgical treatment. Am J Surg 1953; 107: 415.

6. Caggiati A. Fascial relationships of the short saphenous vein. Journal of Vascular Surgery. 2001. 34(2): 241-246.

7. Caggiati A, Bergan JJ, Gloviczki P, et al: Nomenclature of the veins of the lower limbs: An international interdisciplinary consensus statement. J VascSurg 2002; 36:416.

8. Cockett $\mathrm{Fb}$. The pathology and treatment of venous ulcers ofthe leg. Br J Surg 1956; 44: 260-278. 
9. Dodd $\mathrm{H}$. The diagnosis and ligation of incompetent perforating veins. Ann R Coll Surg Engl 1964; 34: 186-196.

10. Kumar SN, Shirisha M. The Role of Subfascial Ligation of Perforator Veins by Cockett and Dodd Method in the Treatment of Varicose Veins. IOSR Journal of Dental and Medical Sciences 2017 May;16(5):9-18.

11. O'Donnell TF, Burnand KG, Clemensong, Thomas $\mathrm{Ml}$,Browsenl. Doppler examination vs clinical and phlebographicdetection of the location of incompetent perforating veins. ArchSurg 1977; 112: 31-35.

12. Field $P$, Van Boxel $P$. The role of the Linton flap procedure in the management of stasis, dermatitis, and ulceration in the lower limb. Surgery 1971; 70: 920-926.

13. Wilkinson GE, Maclaren LF. Long term review of procedures for venous perforator insufficiency. Surg Gyn Obstet 1986; 163: 117-120.

14. Negus D. Prevention and treatment of venous ulceration. Ann R Coll Surg Engl 1985; 67: 144-148.

15. Cikrit DF, Nichols WK, Silver D: Surgical management of refractory venous stasis ulceration. J VascSurg 1988; 7:473478.

16. Stuart WP, Asam DJ, Bradbury AW, Ruckley CV. Subfascial endoscopic perforator surgery is associated with significantly lessmorbidity and shorter hospital stay than open operation, Br J Surg. 1997. 84: 1364-65.

17. Sybrandy JE, van Gent WB, Pierik EG, Wittens $\mathrm{CH}$. Endoscopic versus open subfascial division of incompetent perforating veinsin the treatment of venous leg ulceration. J Vasc Surg 2001; 33:1028-32.

How to cite this article : G Chandra Shekar Goud. Surgical Treatment of Incompetent Perforator Veins by Subfascial Ligation.Perspectives in Medical Research 2021; 9 (2):53-57 DOI:10.47799/pimr.0902.12

Sources of Support: Nil, Conflict of interest: None declared 